PART 2

Land Dynamics and Livelihoods in South-East Asia 
James Zhan, Hafiz Mirza, and William Speller - 9789004304758 Downloaded from Brill.come4/26/2023 12:59:50PM via free access 


\title{
The Impact of Larger-Scale Agricultural Investments on Communities in South-East Asia: A First Assessment
}

\author{
James Zhan, Hafiz Mirza, and William Speller
}

\begin{abstract}
Since the mid-200os, corporate sector investments in agriculture in developing countries have increased sharply, driven by rising commodity prices, the strategic concerns of food-importing countries, and commercial opportunities. Using the findings of fieldwork conducted by UNCTAD and the World Bank in countries across Africa and Asia, this chapter focuses on the impact of such investments on communities in SouthEast Asia. Relying on interviews with representative of the companies concerned and with members of local communities, as well as other stakeholders, carried out using a dyadic approach, the chapter provides detailed findings on the impact of investments in areas such as employment, incomes, land rights and the environment. It shows that both beneficial and negative consequences of agricultural investments can be traced to specific factors, such as decisions taken by investors (and governments) at the early stages of investment processes, the business models utilised, and investor-community relationships, as well as the degree to which responsible approaches are built into operations. The findings on Asia, as well as from the wider study on which this chapter is based, offer valuable information for governments, investors and civil society groups with regard to designing policies and practices, and to establishing relationships between these actors and monitoring areas relevant to the impact and performance of investments.
\end{abstract}

The challenges facing global agriculture in the coming decades are monumental, both as a provider of food and, more broadly, as an engine of growth in developing countries. The sector will have to feed a projected population of 9 billion people by 2050. The Food and Agriculture Organization (FAO) estimates that an average annual investment of USD 209 billion is needed to meet the projected demand for food in 2050 - and even more is required

(C) Graduate Institute of International and Development Studies, 2016 | DOI 10.1163/9789004304758_005 This is an open access chapter distributed under the terms of the Creative Commons Attribution- 
to eliminate hunger, and target poverty and malnourishment (FAO, 2012a). Moreover, faced with a number of common economic, social, and environmental challenges, developing countries require long-term sustainable, increased investment, including investment in agriculture; and in this context an additional average annual investment of some USD 250 billion per year until 2030 is required (UNCTAD, 2014). However measured, the agricultural investment gap is enormous and in many developing countries will most likely require larger scale corporate investment, over and above existing sources.

The central role of smallholder farmers' investment in any strategy for promoting agricultural development is widely recognised (IFAD and UNEP, 2013; HLPE, 2013). But since the mid-200os, corporate sector interest in agriculture in developing countries has increased sharply, driven by rising commodity prices, the strategic concerns of food-importing countries, and various commercial opportunities in the sector. Corporate investment, both foreign and domestic, in agriculture has jumped accordingly, coming not only from traditional investors such as agribusiness enterprises, but also from state-owned enterprises and sovereign wealth funds, as well as private equity and other investment funds, although there is a high degree of uncertainty regarding scale, source of investment, and geographic scope (Schoneveld, 2014; FAO, 2012a; Anseeuw et al., 2012; UNCTAD, 2009).

Much of the research on investment in agriculture to date has focused on Africa, but Asia—especially South-East Asia—has also been a major target for investors. For instance, according to data available to UNCTAD, the stock of foreign direct investment (FDI) in 2012 in Cambodia, Malaysia, and Vietnam stood at USD 1.1 billion, USD 3.8 billion, and USD 3.8 billion, respectively (all of which figures are probably underestimates). Moreover, for some very poor countries such as Cambodia and the Lao People's Democratic Republic, investment in agriculture constitutes a very large share of total FDI (Figure 4.1), which reflects the larger number of investments from Cambodia in the sample. The following figure is based on recent flow data, but stock data are not too different, albeit highlighting the significance of FDI in agriculture in SouthEast Asian countries such as Malaysia and Indonesia, historical beneficiaries of investment in agriculture.

After decades of struggling to attract a significant level of corporate investment, including FDI, to their agricultural sectors, developing countries are now faced with a challenge: in what ways should they accept the type, size and number of such investments in order to maximise development benefits and minimise socio-economic and environmental risks (Deninger and Byerlee, 2011; Human Rights Council, 2011; Vermuelen and Cotula, 2010; Mann and Smaller, 2009)? In their initial naïveté as investment in agriculture began to 


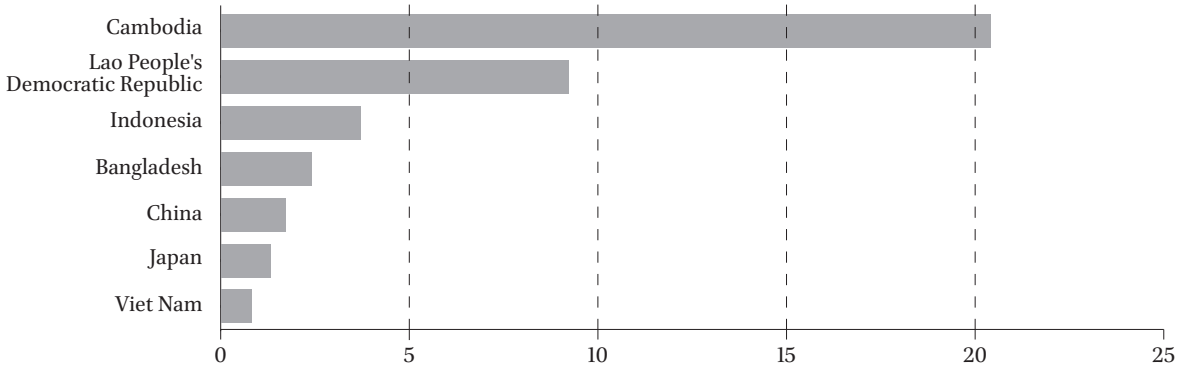

FIGURE 4.1 FDI inflows to agriculture sector as a share of total FDI inflows, 2010-2012 (per cent). SOURCE: UNCTAD, FDI-TNC-GVC INFORMATION SYSTEM, FDI/TNC DATABASE (www.unctad.org/fdistatistics).

surge from the mid-200os many governments encouraged investment without carefully considering the consequences for the economy, rural areas, farmers or communities. As research has multiplied, and more importantly experience has been enriched, in Africa, South-East Asia and elsewhere, it is increasingly being recognised that overall net positive outcomes depend very much on the business models in place, the types of investor-community linkages, partnerships and relations established, etc.

The tenor of the arguments is that of more inclusive business models, achieved for instance by outsourcing as many activities as possible, be this 'outgrower' schemes with nucleus estates/operations outsourcing the farming, or franchised retail dealerships for local-market orientated operations. ${ }^{1}$ Building on such business models, inclusive investor-community relationships can further involve many facets, including issues of ownership and control of assets (for instance, with respect to land and its associated use, communities can interface with investors through sale, lease, equity joint ventures and a large array of other types and combinations of arrangements); the risks and rewards of any arrangements; and the specificities of consultative, partnership, or other routes to communicating and addressing issues (Cotula and Leonard, 2010; Chaimberlain-Ven der Werf and Anseeuw, 2015; Rösler et al., 2013; Gaertner et al., 2014; Eaton, 2001).

However, while inclusive investor-community relationships might be a good idea in principle, in practice a number of major considerations must

1 In contrast, depending on local circumstances including the size of the investment relative to the local economy/community and so on, the investor might, in extreme cases, intertwine with the community through the provisions of education and health services (though in principle this would be taken on by the state as soon as feasible). 
be taken into account when pursuing such goals. First, while the aims might be laudable, the reality could be different and not necessarily because of any intentional malice on the part of any party. For instance, outgrower schemes can widen participation in economic processes and widen the sharing of value added and benefits, but can also lock farmers into the imperatives of the principal investing company, a tension well summed up in the subtitle of De Los Reyes et al.'s (2015) paper on agribusiness and smallholder farmers in the Philippines: A Free Hand, Increased Bargaining Power or Contract Regulation? Secondly, neither investors nor communities are homogenous entities. The benefits and costs of an investment to a community, for example, even if 'net-positive', may fall differentially on the many individuals and groups of which it is composed. Outgrower farmers can be powerful and overbearing; agricultural workers will have different interests to those not engaged in the industry; how can women, minorities and other excluded groups have or attain voice? Thus perceptions of the value of an investment will vary within a community, in addition to the variation of perceptions between communities, investors, governments and other stakeholders. Finally, how an investment interacts with a community depends on a vast range of issues, including the crop involved, the value chain segment of the operation, the scale of the business activities, local conditions and circumstances and so on.

Thus, even if desirable, it is not possible to propose a simple model of investor-community dynamics and even less so one that can be deemed 'inclusive'. However, the literature is beginning to provide contingent good practices and tools that can be drawn on when striving for inclusive investor-community relationships and arrangements, be it in the context of an entirely new investment, or of an attempt to set an existing one on a different course (e.g. Lahiff et al., 2012; FAO, 2013; Deng, 2012). This chapter is based on an ongoing multi-stage study in this vein, whose ultimate aim is to draw detailed, practical knowledge, lessons and good practices from experiences on the ground to inform governments, investors, communities, civil society groups and international organisations engaged in tackling the opportunities, the challenges and the risks of agricultural investments of this type.

The chapter draws on a field-based, intensive survey of the conduct of agricultural operations at 39 larger-scale, mature agribusiness investments in subSaharan Africa and South-East Asia, focusing in particular on their approaches to social, economic and environmental responsibility. ${ }^{2}$ Both the investors and

2 Elements of this chapter appeared in an earlier report (UNCTAD and World Bank, 2014); additional analysis carried out to discern specific issues concerning South-East Asia was conducted for this chapter. 
the communities affected were interviewed. One of the intentions of this stage of the research was not to discern the most important impacts on local communities and the economy, but rather the range of the perceived important impacts of the investments, especially as seen by those locally impacted and other non-business stakeholders. At the same time, perceptions are grounded in realities, such as investors' performance in creating benefits (e.g. net job creation) or imposing costs (e.g. on the environment), albeit the perceived impacts will vary depending on a number of factors, including - for instancethe characteristics of the investment or the type of relationship between it and respondents. Hence the chapter includes discussion of, for example, investments with outgrower schemes, the performance of the investment, and the investor's approach to responsibility and sustainability. A critical incidents instrument was used to discern the range of impacts from the community and local stakeholder perspective.

This chapter examines the impacts of investments in the South-East Asian countries visited (Cambodia, Laos, Vietnam, Indonesia, and Malaysia), including impacts on land rights and access to land, drawing primarily on the answers received from local communities and stakeholders; at the same time it assesses how these impacts are influenced by the type of operations or decisions made by investors. ${ }^{3}$ About a quarter of the investments surveyed were in South-East Asia, so — where relevant or useful—cross reference is made to the fuller sample of responses.

\section{$2 \quad$ Methodology}

A quota-based sample selection procedure was used to identify investors, drawing from a larger population of investors. The quota selection was based on a number of salient variables, including the size of the relative investment, coverage of different business models and value chains, inclusion of different types of companies and funds, coverage of key home and host countries (including investors from developed and developing economies), different crops and so on. The objective was to obtain a diverse sample of investors.

The sample includes both domestic investors and foreign investors from a range of countries, developed and developing. Of the ten investors, four were

3 Throughout this chapter the terms 'investment' and 'investor' are used interchangeably to describe the agribusinesses examined in this survey. Investment in agriculture involves a much wider set of actors apart from large-scale agribusinesses, and includes-most notably—small farmers investing in their own farms. 
pure estate business models, four were processing operations and two were nucleus estate with outgrower models. The products included palm oil, rice, rubber, spices, vegetables, animal feed, and coffee. The size of land allocation ranged from less than 100 hectares to over 50,000 hectares. As such, the sample reflects a broad spectrum of agricultural investments. In South-East Asia, the sample comprises five investments in Cambodia, two in Vietnam and one each in Indonesia, Malaysia, and Lao People's Democratic Republic. Three investors were domestic, two were Thai, and one each were from India, China, Singapore, the UK, and the USA, respectively. The main products were palm oil (three investments) and rice (two), while there was one investment each in rubber, spices, vegetables, animal feed, and coffee. Five investments were operating on less than 100 hectares, three on between 100 and 10,00o, one on between 10,000 and 50,000, and one investment had a land allocation greater than 50,0000 hectares.

Interviews were conducted on a confidential basis. This was an important condition for investors to be able to share information in a frank and open fashion. Nevertheless, the sample was constrained in that it could only include those investments that were willing to participate and, indeed, many investors contacted declined to participate or did not respond to our requests. In that regard, there is some bias in the sample towards relatively 'good' investors - that is to say, those with social and environmental programmes and those performing better operationally and financially. One would expect that these investors would be more likely to agree to allow researchers on-site. That caveat must be acknowledged but it should not be overplayed. In fact, the sample contained several investors that have been portrayed in a negative light in the media or by civil society groups.

Researchers spent around two to three days on-site with each agribusiness, conducting interviews with senior management to complete a semi-structured questionnaire, covering financial, human resources and operational information on the investment, as well details of the investor's approach to a wide range of socio-economic and environmental issues. ${ }^{4}$

4 The range of operational questions/variables included an orientation of the farm/business and its operations; copies of any useful background documents-farm map, concession agreement, model employment contract, environmental impact assessment, organogram, etc.; details of ownership structure and entities; details of farm size and enterprises; history of the operation and the surrounding area; personnel details-numbers, structure, employment conditions, training, etc.; outgrowers' details—contractual arrangements, prices, quality requirements, etc.; markets for product(s) and sources of inputs; perspectives on the success of the investment and the constraints experienced; and tax and incentives. A study of the investor's approach to social and environmental issues enabled an assessment of the extent to which a responsible agricultural approach to investments was being taken. These 
A further two to three days were spent interviewing a wide range of stakeholders in local communities. These interviews were conducted on a confidential and anonymous basis and in an open-ended fashion, allowing stakeholders to raise the issues that are important to them. This approach was taken because (a) the intention was to elicit the issues and obtain some sort of 'qualitative weighting', without assuming that the results were definitive (the findings will be used to partly establish the parameters and framework for future work); and (b) when being asked for details of actual situations, interviewees can respond concretely not formulaically, and the interviewer is able to tease out issues during the discussion. The researchers sought to capture the views of a broad cross section of the community and other local stakeholders. Figure 4.2 provides the salient characteristics of the sample of stakeholders. One-third of the community interviewees were women. In total, 93 separate interviews were conducted. Some interviews included more than one person such that the total number of persons interviewed was 154 .

In addition to the first-hand data obtained, media, civil society and other reports on each investor were consulted (including internal reports and documentation). A number of interviews were conducted with NGOs working on relevant issues, such as land rights or the environment, in the countries visited. These materials helped inform the thinking of the researchers, improved understanding of local contexts, and provided another lens through which to view information obtained through the fieldwork.

The write-ups of the company questionnaires and stakeholder interviews were imported into Nvivo, a software package designed for the analysis of large amounts of qualitative and quantitative data. The programme allows the researcher to classify (or 'code') the data according to particular themes (e.g. employment, resettlement, prices for outgrowers). Nvivo was also used to facilitate the quantification of qualitative socio-economic and environmental impacts obtained during the stakeholder interviews. This is in addition to the pure qualitative assessment of the extensive information received during the fieldwork, which was sorted, compared and analysed on a purely qualitative basis.

The remainder of this chapter is accordingly structured as follows: Section 3 provides a high-level assessment of the socio-economic impact of the investments studied, based on quantitative summary measures of information

questions/variables include land rights and natural resource rights; food security; consultation procedures; transparency; community development and social sustainability; impact assessments and monitoring; environmental impact and sustainability; grievance and redress mechanisms; human rights and best practice policies; and women and vulnerable communities. 


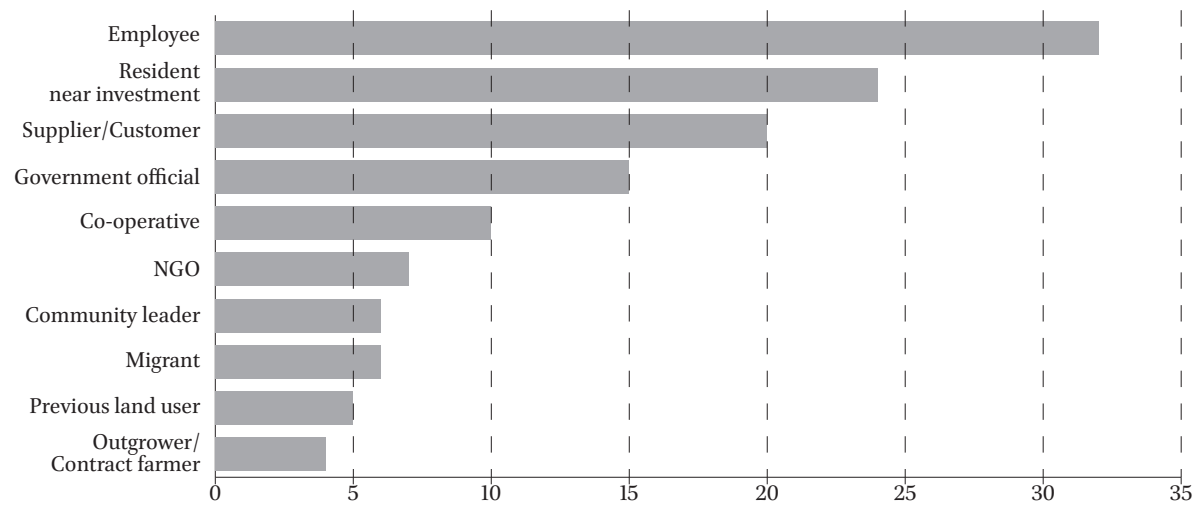

FIGURE 4.2 Number of community and stakeholder interviews and their relationship with investing companies ${ }^{(a)}$

(a) Refers to the number of interviews conducted, some of which may have included multiple interviewees. More than one category can apply to each interview: for example an employee who was also a previous land user. SOURCE: UNCTAD, FDI-TNC-GVC INFORMATION SYSTEM, FDI/TNC DATABASE (WWW.UNCTAD.ORG/FDISTATISTICS).

obtained in stakeholder interviews. It then provides more detail on the key issues identified using a quantitative and qualitative analysis of the material obtained in both stakeholder interviews and interviews with investors. Section 4 translates those findings into potential policies and practices that can be applied by investors, governments and civil society groups to maximise benefits and minimise risks, by applying observations of what has worked and what has not worked at the investments studied. Finally, Section 5 concludes with a discussion of complementary work and future research.

Findings: The Socio-Economic Impact on Communities in SouthEast Asia

\subsection{Overall Assessment}

The investments studied generated both positive and negative socio-economic impacts on surrounding communities and host countries. Figures 4.3 and 4.4 show the most common positive and negative impacts of the investments surveyed-as mentioned during the community and stakeholder interviews detailed in Figure 4.2-providing an overview of how these investments were perceived by those affected by them. 


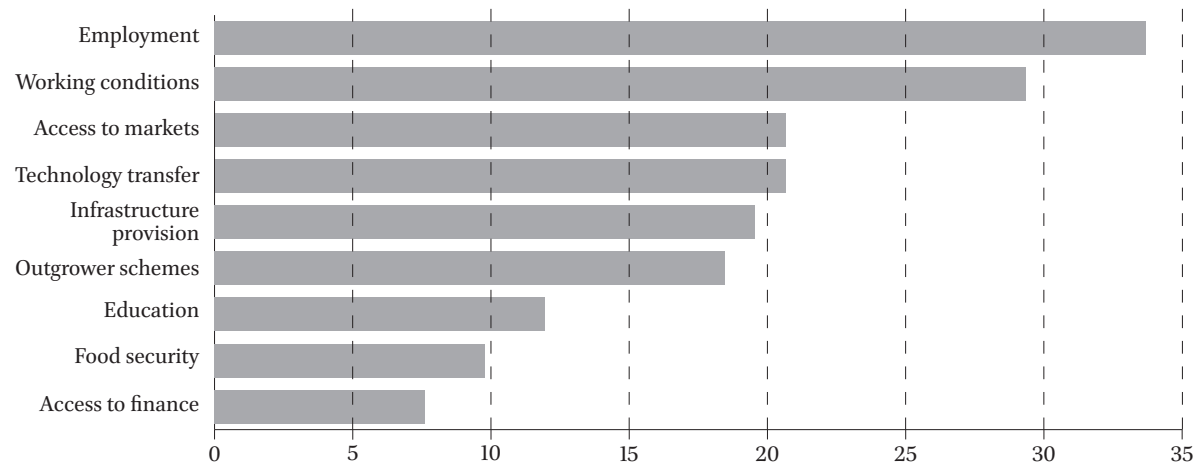

FIGURE 4.3 Share of stakeholder interviews that mentioned a positive impact, by issue: investments in Asia.

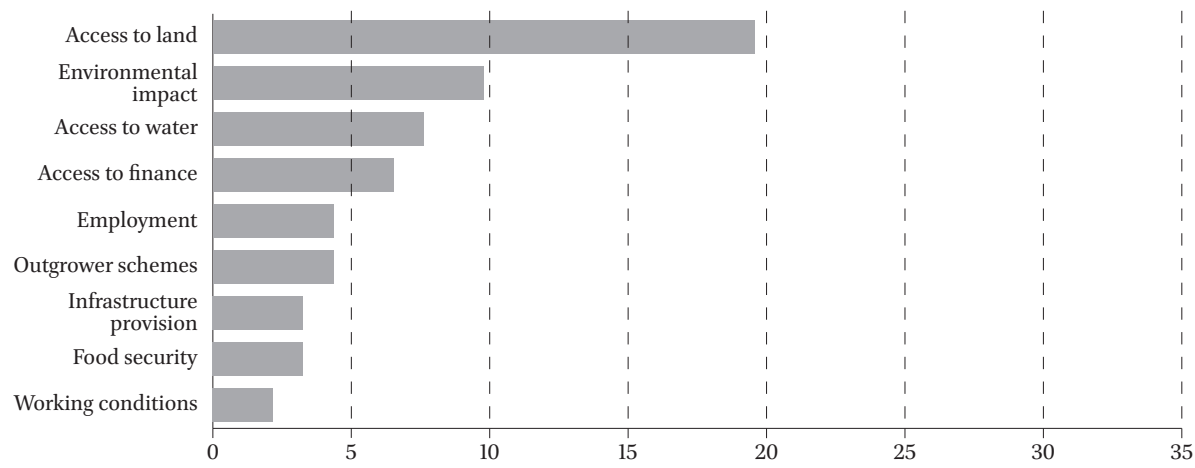

FIGURE 4.4 Share of stakeholder interviews that mentioned a negative impact, by issue: investments in Asia.

Notes: Figures 4.3 and 4.4 were created by classifying information from stakeholder interviews into whether the investment was perceived to have had a positive or negative impact, with the information further categorised by issue within each of these two top-level classifications. For example, an interviewee who stated he was happy to have a job with the investor would be classified as having described a positive impact with respect to employment. Some issues appear as both a positive and a negative impact because there can be both positive and negative dimensions to an investment's impact with respect to each issue. For example, an investor may have improved local water access by installing hand pumps, but may also have had a negative impact by polluting water sources used by local communities due to environmentally unsound agricultural practices. In total, 93 separate interviews were conducted. Some interviews included more than one person such that the total number of persons interviewed was 154.

SOURCE: UNCTAD-WORLD BANK SURVEY OF RESPONSIBLE AGRICULTURAL INVESTMENT DATABASE. 
Overall, the indications are that local communities and other stakeholders interviewed felt that the benefits of the investments outweighed the negative impacts (Figure 4.5). Nevertheless, there is a wide range of outcomes arising from these investments in terms of their socio-economic and environmental impacts, their broader impact on the host country, and the operational and financial success of the investment itself. There are some operations that have generated mostly positive perceived outcomes, while others have produced mostly negative ones (Figure 4.6). Most exhibit a mixture of positive and negative impacts, performing well with respect to some aspects, but with significant room for improvement with regards to others. Investments in Asia were distributed throughout the sample, indicating that they had not systematically performed better or worse than investments in Africa.

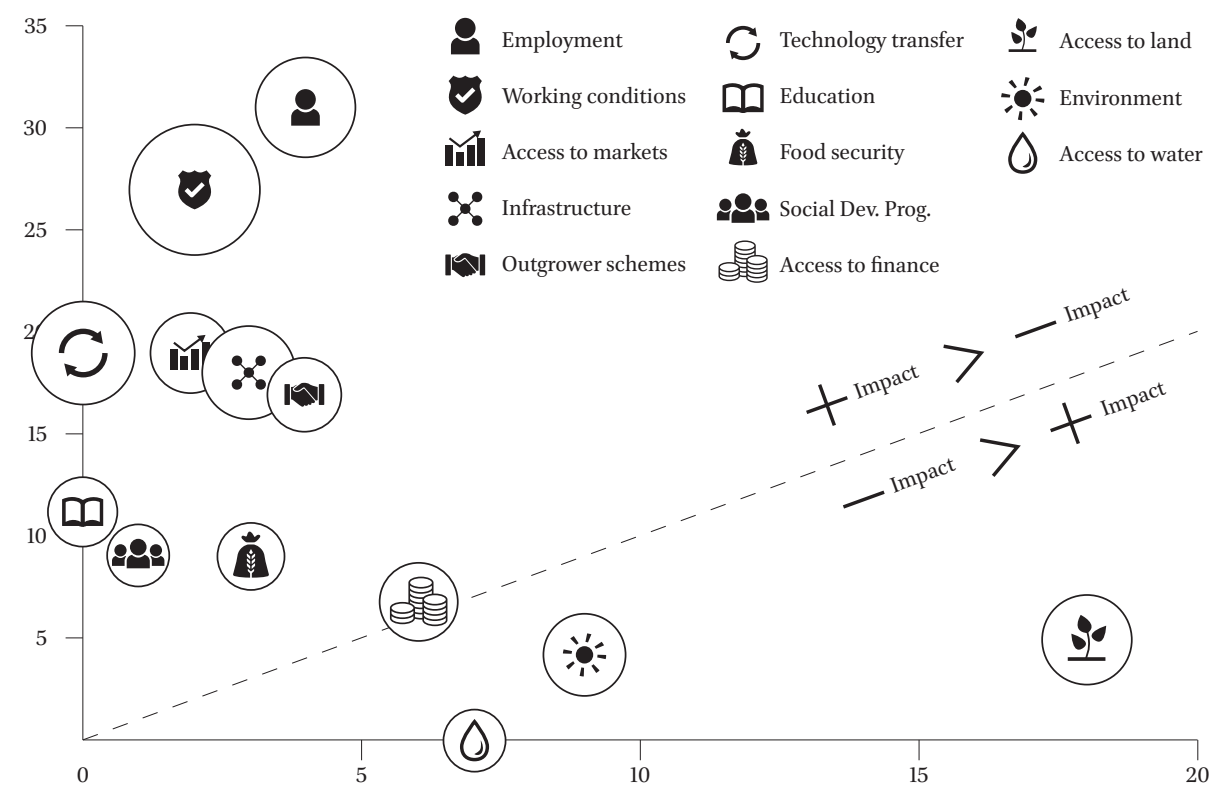

FIGURE 4.5 Stakeholder perceptions of positive and negative impacts of investments in Asia, classified by issue ${ }^{(a)}$.

(a) The vertical axis shows the number of stakeholders who mentioned the investment as having had a positive impact on them with regard to that issue. The horizontal axis shows the number of stakeholders who mentioned the investment as having had a negative impact. The size of the bubbles represents the relative frequency with which each issue arose in stakeholder interviews, whether in a positive, negative, or neutral context. SOURCE: UNCTAD-WORLD BANK SURVEY OF RESPONSIBLE AGRICULTURAL INVESTMENT DATABASE. 


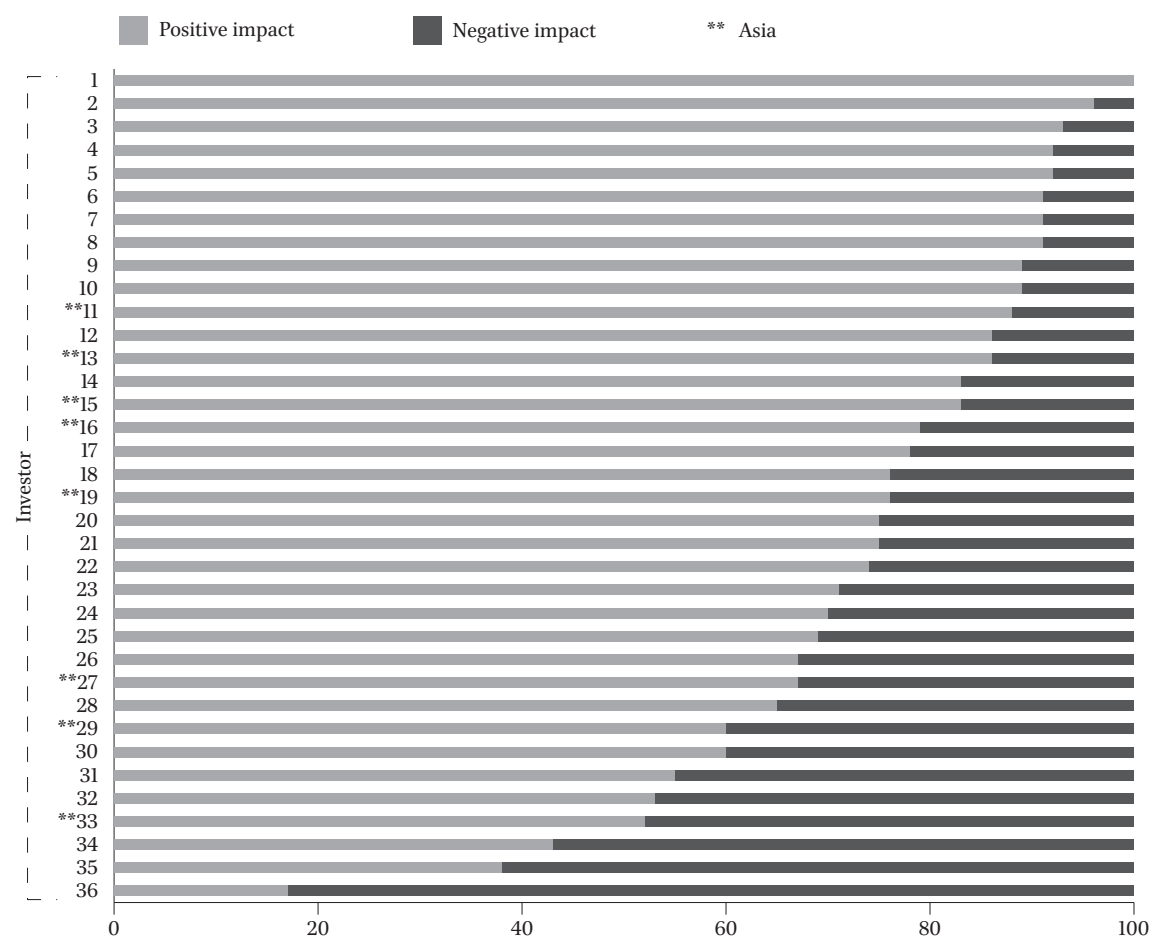

FIGURE 4.6 Share of positive / negative socio-economic impacts mentioned in stakeholder interviews, entire sample ${ }^{(a)}$.

(a) All impacts of the investment mentioned in stakeholder interviews are classified as 'positive' or 'negative.' Chart shows the balance of positive and negative mentions for each investor.

SOURCE: UNCTAD-WORLD BANK SURVEY OF RESPONSIBLE AGRICULTURAL INVESTMENT DATABASE.

While figures 4.3-4.6 present an overview of the quantification of socioeconomic and environmental impacts obtained during the stakeholder interviews, the detailed analysis in the following section relies on a qualitative assessment of the extensive information gathered during the fieldwork, information that has been examined and assessed on a primarily qualitative basis.

\subsection{Detailed Findings}

3.2.1 Employment

Job creation was the most frequently cited benefit arising from the investments. The investments studied in Asia employed around 7,000 people (Table 4.1) in total. This refers to direct employment by the investor, the number of indirect jobs created being difficult to assess. As an indication of the 
possible scale of further job creation, two rice producers in Cambodia employed 12,500 and 30,000 contract farmers, respectively (though these farmers may not work exclusively for these investors). Similarly one coffee processor contracts to 1,500 distributors in Vietnam, and another works with 2,80o farmers, also in Vietnam. Beyond this, there are various multiplier and other indirect effects leading to further jobs being created-or destroyed. To get a full idea of the impact on job creation/destruction, further work is required.

Direct job creation was relatively more land-efficient in Asia- that is to say approximately 14 hectares per job in Asia (Table 4.1) — compared with investments in Africa. This is partly because the sample of Asian investors included more processing operations, underscoring the point that the benefits of investment in agriculture can arise even in the absence of large-scale land allocations. Large land allocations do not necessarily create the most jobs per hectare.

The share of permanent jobs as a proportion of total employment was higher in Asia than in the full sample, at around 70 per cent, compared with 50 per cent for the full sample. This is reflected in the more positive perception of working conditions that emerged from stakeholder interviews in Asia. Most investments visited paid higher wages than those available locally and those wages were sufficient for employees to maintain a decent standard of living. Several interviewees compared wages at agricultural investments favourably with those available in other industries in which foreign investors were present (for example, the garment industry in Cambodia).

TABLE 4.1 Direct employment created, descriptive statistics: Asian investments

Sum of Mean Median Max. Min. Female Expat Hectare/

Asian

$\operatorname{share}(a) \operatorname{share}(a)$ job

Invest.

\begin{tabular}{lrrrrrrrr}
\hline Total formal employment & 6,825 & 683 & 252 & 2,647 & 120 & $32 \%$ & $1 \%$ & 14 \\
Permanent & 4,655 & 466 & 145 & 2,647 & 40 & $26 \%$ & $2 \%$ & 20 \\
Temporary/Casual/ & 2,170 & 217 & 20 & 1,200 & 0 & $38 \%$ & $0 \%$ & 44 \\
Seasonal & & & & & & & & \\
\hline
\end{tabular}

(a) Not all investors provided female and expat share figures. These percentages are based on the subset of investors that did (i.e. eight out of ten).

SOURCE: UNCTAD-WORLD BANK SURVEY OF RESPONSIBLE AGRICULTURAL INVESTMENT DATABASE. 
Employment of expatriates was low in the sample, but not all jobs went to the population directly surrounding the investment. And expatriates were over-represented in management positions. In almost all cases, semi-skilled, unskilled, and casual or seasonal employment was sourced from the host countries. But employees were not necessarily from surrounding communities and sometimes came from other parts of the country, including the capital city. This in some instances led to tensions between the local community and the domestic migrant community.

There was a considerable gender imbalance at most investments, both in terms of numbers and the types of jobs on offer. Only around one-third of employees were women, and they were more likely to hold casual, temporary, or seasonal jobs. As such, women were overrepresented in the worst paid and most insecure jobs.

\subsubsection{Impact on Outgrowers}

Investors also contributed to employment opportunities by providing a stable market for outgrowers' produce: for example, the 11 investors with outgrower schemes helped to support-at least in part-the livelihoods of 30,000 contract farmers in total. According to stakeholders interviewed, the concomitant rise in rural incomes contributed positively to food security, directly and indirectly. As such, outgrower schemes interact significantly with several of the key benefits shown in Figure 4.3, notably technology transfer, access to markets, and food security. Impacts therefore had a wider dispersal vis-à-vis stakeholders than in cases where the investments were estates only, and perceptions of positive impact from the investment were generally higher, although arguably some of the perceived negative impacts were more diffused (i.e. blame, where it existed, assigned to outgrower farmers and not just to the principal investor). At the same time, the perceptions of the outgrowers also need to be taken into consideration.

Outgrower schemes can be effective in supporting livelihoods while allowing people to retain their most valuable asset-their land. Governments should consider which investors and business models are likely to maximise direct and indirect employment as these are key benefits of agricultural investment. Governments should consider the whole value chain and promote value-addition downstream of the raw materials produced from the land made available (a number of investors were processors, for instance), thereby maximising employment and other benefits. However, marginalised groups, including women and minorities, were less likely to participate in outgrower schemes. Consideration should be given to how to improve access for these groups. 
The main advantage for outgrowers selling to major agricultural investors was higher prices and reliable, timely payments - a perception reiterated by senior management and outgrowers alike. But even major investors faced cash flow problems and some outgrowers-particularly those who have been assured a guaranteed minimum price for all their produce-have sometimes not been paid according to the agreed terms. More commonly, outgrowers lost money owed when investors faced capacity constraints. For crops that must be processed soon after they are harvested-including rubber, sugar, and palm oil—this occurred when investors did not facilitate timely pickups to transport outgrowers' produce to the processing site, or lacked sufficient factory space to process the raw materials once there.

Outgrowers tended to feel excluded from price-setting mechanismsprices were usually set by the government, major industry players, the investors themselves, or a combination of these actors, always based in part on international market prices for the commodity. Despite company efforts to inform their outgrowers of current prices and mechanisms, pricing was often contentious, with many outgrowers voicing concerns about how their produce was quantified and assessed for quality, as well as about the final sum they received. Thus there is a need for good communication between farmers and company management about how prices are set, and for improved safeguards to ensure these prices are appropriately remunerative.

For instance, in Indonesia the price paid in each region for fresh fruit bunches of oil palm was set monthly through a multi-stakeholder process, involving members of the provincial plantation agriculture department, company management, and representatives of cooperatives. Those involved used a predetermined formula to fix the price; and one variable, the oil extraction rate, was the subject of much negotiation each month. Once a price was agreed, a formal notification was signed by the government, company, and outgrower representatives, obliging the investor to pay the set price.

\subsubsection{Land Rights and Access to Land}

The most prominent negative impacts arising in the investments examined were disputes over access to land. People's lives in rural communities are intimately tied up with their access to land and other natural resources and the arrival of an investor can have significant implications. Interviewees had, on balance, negative perceptions of the impact of investments across a range of land-related issues, including previous use of the land; the terms of, and process for, land acquisition; resettlement procedures; access to, and use of, the land by communities; the degree of land use practiced by the investor; and the rights of pastoral farmers and other customary land users. 
Local communities often did not understand what rights to land they have under the laws of the country and frequently did not have formal titling deeds, even if they had been working the land for many years or generations. The situation was more complex in post-conflict countries where formal cadastral records had been lost during the conflict and a national land titling process was in progress.

Another common grievance was the failure to use the land in accordance with expectations. The under-use of allocated land was, however, a more prominent negative issue in Africa as compared with our Asian sample. Nevertheless, one investor in Cambodia appeared to be using its large land allocation for timber extraction only and not respecting its commitment to subsequently develop a rubber plantation on the land cleared. In this and other cases in the country, the failure to develop land resulted from inadequate financial capacity. Some investors have sufficient financial backing to acquire the land but not to develop it.

This risk can be minimised through full and early assessment and consultation of existing formal and informal rights to, and usage of, the land. Such consultations should be first and foremost the responsibility of the investor, with appropriate monitoring from state and non-state actors. It proved perilous to leave consultations to the host government; or for the investor to assume that the land acquired was being provided by the government without any existing land disputes. Similarly, it was unsatisfactory to outsource the consultation process to third parties such as land agents. Governments or land agents sometimes claimed to have 'prepared the land' - that is, left it issue-free for the investor to take over. Their claims that all land conflicts had been dealt with often proved spurious.

A lack of transparency with regard to the terms and process of land acquisition had important consequences. Uncertainty about investor actions and intentions created a sense of fear and resentment within communities nearby, with adverse consequences for the investment. For example, some members of one local community asked the researchers whether the investor nearby planned to take their land. This situation could in part have been avoided by greater transparency about the investor's operation.

Beyond such general aspects, a set of more financially-inclusive business models have begun to emerge and have been successful in forging partnerships with local communities, including over issues related to land. In explicit revenue-sharing arrangements, for example, an investor operates on community or native land and, rather than renting the land, enters into a revenue-sharing arrangement based on a certain percentage of the monthly turnover. These schemes are beneficial because they provide a continuous revenue stream 
across generations and genuine community-private partnerships in which communities take an interest in the success of the operation.

Since 2011, a palm oil company in Sarawak (Malaysia) has adopted a new business model whereby the company rents land from owners of Native Customary Rights (NCR) land to develop it for the cultivation of oil palm for a period of 30 years, after which the land and the palms will be returned to the land's owners. The company will bear the costs of development and after the third year - when the palms start to bear fruit - the company will pay each owner a fixed rental per tree until the expiry of the 30-year lease. The company has chosen this model as it is viewed as a more equitable and fairer proposition than the approach used by other companies in Sarawak whereby about 60 per cent of the ownership of the land would eventually be transferred to the company and the owners of NCR land would have only 30 per cent ownership.

\subsubsection{Building In Responsibility and Sustainability: Initial Phases of the Investment}

A key finding is that investor and host country actions at the pre-investment stage and during the initial phases of the investment are critical. This includes the investors' approach to consultations and engagement with local communities, impact assessments and transparency, and the host country government's pre-screening and monitoring of investors. While it is important that socially and environmentally responsible practices are embedded within the operation and monitoring of an investment on an ongoing basis, it is the processes followed, decisions taken, and requirements enforced in these early stages that dictate much of the future path of the investment.

In the investments studied, consultations were a key step in developing a strong relationship between the investors and the local communities. This generated more positive socio-economic outcomes and was in the interests of the investors because it contributed to financial and operational success, in particular by minimising the risk of land disputes. While initial consultations could be time-consuming and expensive, particularly for new investments, attempts to rush the process - due to the commercial expediency of getting the land acquisition settled quickly-led to negative long-term ramifications, both for the businesses and for the local communities, over a protracted period.

As mentioned above, stakeholder consultation was most effective when it was the responsibility of the investor. Host governments should establish regulations or guidelines for the conduct of such consultations and stringently monitor adherence, but not conduct these activities for investors. Ensuring community interests are represented requires the involvement of state and 
non-state actors. Some countries have enacted legislation requiring government oversight of community consultations. This has helped to ensure that investment projects have supported national and local development goals.

Formally established procedures through which stakeholders can raise grievances and seek redress also contributed to better relations with local communities. The best examples of grievance and redress mechanisms were those that were more formalised, typically involving a Community Liaison Committee on which the investor and the local community were represented.

In many cases, pre-screening of foreign investors can be improved to increase the prevalence of investors likely to make a positive contribution to the host country. Pre-screening should include, as a minimum, assessment of investors' financial strength and technical capabilities, their proposed approach with respect to consultations and impact assessments, and their commitments in terms of the benefits that the investor will bring to the host country.

Pre-screening, however, should not extend to producing business plans on behalf of investors, plans that are then in effect sold as part of the concession agreement. Business plans provided by host governments were often based on unrealistic assumptions and sub-standard assessments of crop suitability and other environmental factors. A rubber plantation in Cambodia was being operated on soil that interviews with surrounding communities quickly identified as being inappropriate for rubber production.

Social and environmental impact assessments (SEIAS) are another important tool for building responsibility and sustainability into the initial phases of an investment. There was a noticeable trend of investors taking their environmental responsibilities more seriously, undertaking social and environmental impact assessments, employing internal environmental management plans (EMPs), and making public their environmental policies. Investors cited increasing pressure from host country governments and the demands of certification processes as key drivers for this trend.

Yet SEIAS were too often 'box ticking' exercises, carried out merely to secure a license to operate rather than used as a tool to be actively incorporated into the conduct of the business. Many impact assessments were one-off assessments, not accompanied by a system of ongoing monitoring and adherence to recommendations for changes to operations. Some EMPs only existed on paper and were not authentic tools used to manage the environmental impact of the investment.

As with consultations, the government's role in impact assessments was most effective when limited to monitoring and ensuring proper conduct and implementation. This included providing detailed legal requirements covering 
what is expected of investors and the stipulation of requirements for thirdparty, independent auditing of such assessments.

SEIAs should also be transparent. In Malaysia, for example, assessments are published on the Department of Environment website. In other countries, much less information is available publicly. This lack of transparency applies to other areas too. In general, there was an insufficient amount of publicly available information to ensure the fully transparent and accountable conduct of agricultural investment.

Once these initial phases have been completed, commitments made as part of the consultation, screening, and impact assessment projects need to be monitored by the host government. Ongoing monitoring of agricultural investments by host governments was often limited and productivity-focused. All investors were subject to some form of monitoring, typically by departments of agriculture, land, labour, or the environment. But when government officials came to assess agricultural concessions, they often focused on ensuring the investor was meeting productivity targets, with little monitoring of the socioeconomic and environmental impacts of an investment. The results or details of government monitoring were rarely made publicly available, making it difficult for other interested parties - be they local residents or civil society representatives - to hold investors to account.

Some governments had allowed foreign investment in agriculture to proceed at a pace beyond their ability to realistically assess and monitor the investors. Wherever necessary, governments should consider how to improve their monitoring capacity and, if necessary, consider slowing down the approval of new agricultural investments.

\subsubsection{The Financial and Operational Performance of Investors}

A somewhat surprising finding from the overall study, at least at first glance, is that many investors were in operational and financial difficulties. Around 45 per cent of investors were materially behind schedule or operating below capacity. About the same share were unprofitable at the time of the survey. The Asian investments tended to be performing better, with around 80 per cent profitable at the time of the survey and around one-third behind schedule.

A key distinction between the better or worse performers is linked to whether they have acquired substantial amounts of land or not. The Asian experience reflects findings in the wider sample that processing operations or those that do not involve large land allocations tended to be more successful - that is to say, processors/outgrowers as opposed to estates/estates plus outgrowers (Figure 4.7). Many of the latter investments were spending significant time and resources dealing with land disputes that could and should have 


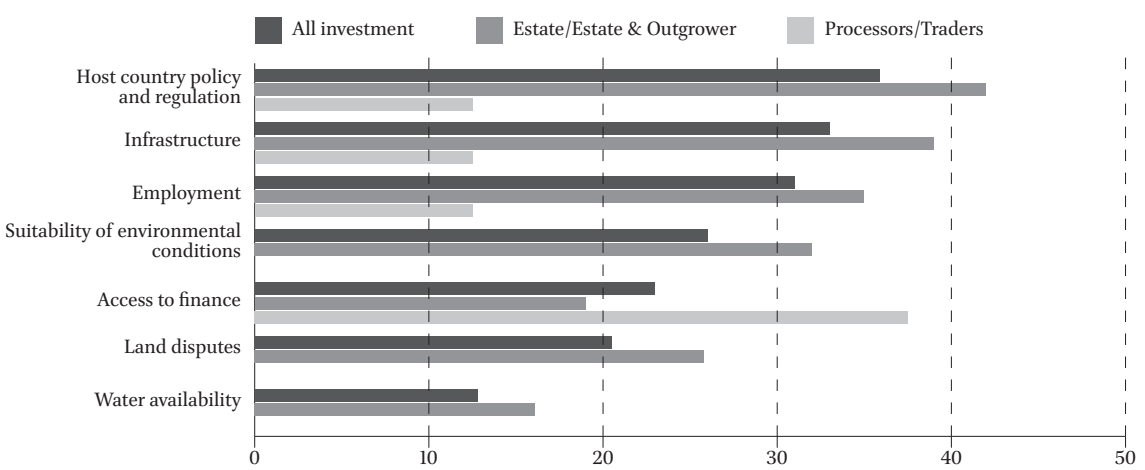

FIGURE 4.7 Percentage of investors mentioning particular constraints on operations. SOURCE: UNCTAD-WORLD BANK SURVEY OF RESPONSIBLE AGRICULTURAL INVESTMENT DATABASE.

been identified and appropriately handled via pre-investment consultation and impact assessment procedures.

Investors highlighted a number of constraints that hindered their prospects of success (Figure 4.7). They noted the importance of host country governments in creating an enabling environment that allows investors to survive, thrive and contribute to the local community and the broader economy. International investors in several countries experienced a lack of a clear, transparent and consistent approach towards foreign investment in agriculture, including policies and procedures for the purchase or lease of land. Access to finance, inadequate infrastructure and difficulties in sourcing local, qualified staff were other key constraints on profitability.

Financial and operational success is an essential precondition for agricultural investments to make a positive contribution to development, whereas failure can create lose-lose-lose situations for investors, host countries and local communities alike. In this regard, investors noted the importance of striking the right balance between, on the one hand, imposing necessary requirements and regulations that promote responsible investment, and, on the other, ensuring that requirements were not so burdensome as to preclude much needed investment by agribusinesses.

A key finding of this research is that a potentially win-win situation vis-à-vis investment performance and investments' wider positive economic, social, and environmental impact is achievable. In the survey, investors that were financially and operationally successful tended also to be those that had the most positive impact on their host economies and surrounding communities - the result of more sophisticated approaches to social and 
environmental responsibility. Similarly, those investments that were wellintegrated within the host country and surrounding community were most likely to be financially successful. Investors that acquired land but did not conduct thorough impact assessments and consultations with communities, or left it to host governments to conduct them on their behalf, often found themselves subsequently dealing with costly and time-consuming land disputes.

\subsubsection{Environmental Impact}

Almost all investors had cultivation and operational models the environmental impacts of which are likely to be negative, and the assessment and management of which was often deficient. Most of the cultivation operations visited were undertaking intensive production operations of one or two crops, often involving extensive use of pesticides. Such intensive use of land and water contributes to degradation and depletion of these resources and a loss of biodiversity. Most investors have undertaken some measures to mitigate the negative environmental impact of their operations. Although these are initiatives that should be welcomed, it is important to note that they do not generate a positive or even a neutral environmental impact, but merely reduce to some extent the overall negative environmental impact of the investments studied in this research.

One exception was in Cambodia where one investor is promoting organic farming in a model farm that would comply both with guidelines under the International Foundation for Organic Agriculture (IFOAM) and with Indian Organic Certification Agency (INDOCERT) requirements for production of certified organic products. Agrochemicals and chemical fertilisers are not used. The farm maintains 30 cows to produce its own compost and organic fertilisers from cow dung and urine. Weeding is done manually.

Minimal tillage is practiced and the ground is protected by vegetation (mainly weeds) to prevent soil erosion. Crop rotation is practiced. The company is considering the feasibility of installing windmills to provide electricity to the farm and to the neighbouring village. The model farm is rain-fed for about 7-8 months in the year. In order to ensure that there is an adequate water supply during the dry months, the company has dug a network of 30 water-harvesting and retention ponds at low points around the farm. Rain harvesting is also carried out from the roof of the workers' quarters and other buildings.

More broadly, the environmental impact of the investments studies was difficult to discern, and so will be the subject of further research. Although environmental issues were not raised often in the stakeholder interviews, this 
cannot be taken as an indicator of limited environmental impact. Interviewees would tend to raise only those obvious issues that they directly experience (such as those mentioned above). But most environmental consequences materialise gradually and may not be immediately obvious to surrounding communities. Although some government environmental officials were interviewed, the results tended to reinforce the above conclusions about the inadequacy of environmental monitoring.

\section{$4 \quad$ Lessons Learnt and Policy Implications}

A number of key findings from the research described in this chapter have implications for investors, governments, and civil society. In particular, the research finds that issues such as due diligence, consultations with communities, financially inclusive business models, environmental impact assessments and transparency issues are crucial for investors to get right. In a similar vein, host governments need to pay special attention to aspects such as the pre-screening and selection of investors, ongoing monitoring of investments, conduct of consultations, impact assessments and business plans, phasing of investment approvals, and land rights. Finally, activities such as engagement with investors, monitoring of investors, and helping investors forge partnerships with marginalised groups are areas in which the active participation of local communities and NGOs can make a difference. Building on this, including the broader study of the sample of cases in Africa, it is possible to suggest policies and practices for governments, investors and civil society groups (in Asia and beyond) that, if implemented with due regard to local contingencies, can improve the chances of beneficial outcomes and minimise the risks of negative impacts associated with investments in agriculture. ${ }^{5}$

As discussed in the introduction to this chapter, and reinforced by the empirical findings of this study (and other research), the business models deployed and the investor-community relationships developed are central to both investment performance and impact on communities and economies. The differential outcomes of business models is most readily evinced, for example-in Section 3 of this chapter-in terms of employment generated and the performance of companies; while the investor-community relationship's importance can be discerned most readily in the analysis of land rights/

5 An UNCTAD and World Bank 2014 report provides numerous case study examples of best and worst practices, and a fuller discussion of lessons for investors, governments, and others. 
access to land and investor actions vis-à-vis stakeholders in the early phases of an investment. Some of the key implications of these findings for the policies and practices of investors are:

- Early engagement and consultation with surrounding communities, including previous and existing users of the land.

- Transparency about the operation and ongoing dialogue with stakeholders, including the establishment of a formal grievance procedure.

- Social development programmes that reflect local communities' development visions.

- A financially inclusive business model.

- Proper conduct of social and environmental impact assessments (SEIAs) and their integration within business models.

- Setting of, and adherence to, realistic expectations about the pace of development of operations; use of land in accordance with commitments.

- Phasing of the investment, for example applying for and successfully developing a parcel of land before seeking a larger allocation.

- Fair and adequate remuneration, contractual conditions, and training for employees and outgrowers.

- Resolution of the business model prior to introducing outgrowers.

As knowledge of how to better the impact of investment in agriculture improves, there are policy implications for governments, often as counterparts to those for investors. Thus notable policy considerations for governments include:

- Rigorous pre-screening of potential investors' experience, financial capacity and technical capabilities.

- Obtaining from foreign investors commitments to social development programmes, employment, and other benefits to the host country, as well as a detailed schedule for the development of operations.

- Ongoing monitoring of investors' agreements and commitments.

- Monitoring consultations and SEIAs, but not conducting them on an investor's behalf.

- A clear, transparent regulatory framework for land acquisition (purchase or lease), consultations, resettlement, and compensation.

- Formalised local community tenure rights under a proper land registry system.

- Approval of foreign investment applications in line with the capacity to screen and monitor investors. 
- Encourage phasing of investments, rather than mega-land deals; for example, providing an initial allocation of land, with further allocations contingent upon its successful development.

- Monitoring and enforcement of adherence to environmental and water regulations.

- Encouragement of innovation (new crops, technology, etc.), but not initially on a large scale.

- Reducing red tape and creating an enabling environment for foreign investment and the development of domestic industry.

Finally, civil society groups also have a vital role to play, not least in supporting local communities, for instance in the initial setting up of investment operations and longer-term monitoring. For instance, civil society groups could:

- Engage with investors to help them forge partnerships with marginalised groups and ensure that relevant stakeholders are included in decision-making processes.

- Help local communities to be well-organised, and to understand their rights and how to exercise them.

- Monitor conflicts between investors and stakeholders and constructively draw attention to important issues.

\section{$5 \quad$ Conclusions and Further Work}

The diversity of experiences, performance, and impacts of investments analysed in this chapter suggests that a wide range of factors influence the outcomes of an agricultural investment, and its impact on the local community and economy. Some factors are context specific. As such, one cannot be categorical about the types of investment that are most or least desirable, but business models adopted by investors, and specific approaches, policies, and practices adopted were shown to have a bearing on the outcome of investments. The nature of investor-community relationships, and the distribution of benefits (and costs) between the investor and the community, and within the community (the local economy) itself, also affect the overall impact. As discussed in the previous section, this can lead to actionable policies and practices for investors, governments, and communities.

The study on which this chapter is based has sought to contribute to the growing body of knowledge of what the responsible and sustainable conduct 
of agricultural investment consists of in practical, operational terms for communities, governments, and investors. In addition to the policy lessons outlined above, analysis of the range and type of impacts, and factors influencing the beneficial or negative outcomes of such impacts, can be used in concrete ways. For example, UNCTAD, the International Institute for Sustainable Development (IISD), and the World Bank are putting together a foundation for model contracts/contract clauses for investment in agriculture, using concrete examples of how to maximise the gains and minimise the risks of private sector participation in the agricultural sectors of developing countries, with information taken from this study and other works.

However, effective action by policymakers in specific areas of concern relating to investment in agriculture requires additional thoroughgoing work. Thus, in late 2014 UNCTAD and the World Bank embarked on a further, more concentrated (fewer cases), in-depth (focusing on specific issues gleaned from the first study, with a larger number of community/stakeholder participants) study on a selected sub-group of the original operations/communities visited. Among other aims, this research seeks to investigate the internal differences within local communities in terms of the impact of investments. That is, picking up on the variations in perceptions of impact within the communities mentioned in the introduction to this chapter, the study asks which particular groups or persons win or lose from investments and, more importantly, under what circumstances.

Finally, many of the decisions and actions that determine the ultimate outcome of investments are taken prior to the investment or during its initial phases. For this reason, UNCTAD and the World Bank, along with FAO and the International Fund for Agricultural Development (IFAD), also launched-in 2015-a new field programme working with investors, communities, governments, and other stakeholders from the outset of new operations. The primary objective of this next stage of the work is to infuse responsible and inclusive practices (taken from extant research, as discussed earlier) into agribusiness operations-including vis-à-vis investor-community relationships-from the outset, and to ensure that the outcomes of these operations work to the benefit of local communities, the environment and the economy as a whole. Along the way, the research aims to create context-aware procedures, processes, approaches and documentation - a toolkit, as it were-for building inclusive and development-friendly investment-community relationships and outcomes. 


\section{References}

Anseeuw, W., L. Alden Wily, L. Cotula and M. Taylor (2012) Land Rights and the Rush for Land: Findings of the Global Commercial Pressures on Land Research Project (Rome: International Land Coalition), http:/www.landcoalition.org/sites/default/files/ publication/1205/ILCGSR report_ENG.pdf (accessed on 7 May 2015).

Chamberlain-Van Den Werf, W. and W. Anseeuw (2015) Making Land and Agricultural Investment Work for Development and Shared Prosperity-Assessment of Inclusive Business Models, paper presented at the 2015 World Bank Conference on Land and Poverty, March 23-27, Washington, D.C., https://www.conftool.com/landand poverty2015/index.php/Chamberlain_-_Van_der_Werf-440-440_paper.pdf?page= downloadPaper\&filename=Chamberlain_-_Van_der_Werf-440-440_paper.pdf\& form_id=440 (accessed on 7 May 2015).

Cotula, L. and R. Leonard (eds.) (2010) Alternatives to Land Acquisitions: Agricultural Investment and Collaborative Business Models (London, Bern, Rome and Maputo: IIED-SDC-IFAD-CTV), http://www.ifad.org/pub/land/alternatives.pdf (accessed on 7 May 2015).

Deininger, K. and D. Byerlee (2011) Rising Global Interest in Farmland: Can It Yield Sustainable and Equitable Benefits? (Washington, D.c.: World Bank-International Bank for Reconstruction and Development), http://siteresources.worldbank.org/ DEC/Resources/Rising-Global-Interest-in-Farmland.pdf (accessed on 7 May 2015).

De Los Reyes, V.R., J.L. Capacio, A. Garcia and J.V. La Chica (2015) Agribusiness and Smallholder Farmers in the Philippines: A Free Hand, Increased Bargaining Power, or Contract Regulation?, paper presented at the 2015 World Bank Conference on Land and Poverty, March 23-27, Washington, D.C., https://www.conftool.com/landand poverty2015/index.php/delos_Reyes-642-642.doc?page=downloadPaper\&file name=delos_Reyes-642-642.doc\&form_id=642 (accessed on 7 May 2015).

Deng, D. (2012) Handbook on Community Engagement: A 'Good Practice' Guide to Negotiating Lease Agreements with Landowning Communities in South Sudan (Juba: South Sudan Law Society), http://namati.org/resources/handbook-on-communityengagement-a-good-practice-guide-to-negotiating-lease-agreements-with-landowning-communities-in-south-sudan/ (accessed on 7 May 2015).

Eaton, H. and A. Shepherd (2001) Contract Farming: Partnerships for Growth, FAO Agricultural Services Bulletin 145 (Rome: Food and Agriculture Organization), http://www.fao.org/docrep/o14/yo937e/yog37eoo.pdf (accessed on 7 May 2015).

FAO (Food and Agriculture Organization) (2013) Trends and Impacts of Foreign Investment in Developing Country Agriculture: Evidence from Case Studies (Rome: FAO), http://www.fao.org/docrep/017/i3112e/i3112e.pdf (accessed on 7 May 2015). 
(2012a) The State of Food and Agriculture: Investing in Agriculture for a Better Future (Rome: FAO), http://www.fao.org/docrep/017/i3028e/i3028e.pdf (accessed on 7 May 2015).

(2012b) Voluntary Guidelines on the Responsible Governance of Tenure of Land, Fisheries and Forests in the Context of National Food Security (Rome: FAO), http:// www.fao.org/docrep/016/i2801e/i2801e.pdf (accessed on 7 May 2015).

Gaertner, K.M., F. Ishikawa, T. Masuoka and B. Jenkins (2014) Shared Prosperity Through Inclusive Business: How Successful Companies Reach the Base of the Pyramid (Washington, D.c.: International Finance Corporation), http://www.ifc.org/wps/ wcm/connect/bf203d80463da1548c9obd9916182e35/SharedProsperitythruiBiz FINAL.pdf?MOD=AJPERES (accessed on 7 May 2015).

HLPE (High Level Panel of Experts) (2013) Investing in Smallholder Agriculture for Food Security, A Report by the High Level Panel of Experts on Food Security and Nutrition (Rome: Committee on World Food Security), http://www.fao.org/3/a-i2953e.pdf (accessed on 7 May 2015).

IFAD (International Fund for Agricultural Development) and TechnoServe (2011) Outgrower Schemes-Enhancing Profitability, Technical Brief, September (Rome and Washington, D.c.: IFAD and TechnoServe), http://www.technoserve.org/files/ downloads/outgrower-brief-september.pdf (accessed on 7 May).

IFAD and UNEP (United Nations Environment Programme) (2013) Smallholders, Food Security and the Environment (Rome: IFAD), http://www.ifad.org/climate/resources/ smallholders_report.pdf (accessed on 7 May 2015).

Lahiff, E., N. Davis and T. Manenzhe (2012) Joint Ventures in Agriculture: Lessons from Land Reform Projects in South Africa (London, Rome and Capetown: IIED-IFADFAO-PLAAS), http://pubs.iied.org/pdfs/12569IIED.pdf (accessed on 7 May 2015).

Mann, H. and C. Smaller (2009) A Thirst for Distant Lands: Foreign Investment in Agricultural Land and Water (Winnepeg: International Institute for Sustainable Development), http://www.iisd.org/pdf/2009/thirst_for_distant_lands.pdf (accessed on 7 May 2015).

Rösler, U., D. Hollman, J. Naguib, A. Oppermann and C. Rosendahl (2013) Inclusive Business Models: Options for Support through PSD Programmes (Bonn: Deutsche Gesellschaft für Internationale Zusammenarbeit), http://www.giz.de/fachexpertise/ downloads/giz2014-ib-models-rz.pdf (accessed on 7 May 2015).

Schonevel, G.C. (2014) 'The Geographic and Sectoral Patterns of Large-Scale Farmland Investments in Sub-Saharan Africa', Food Policy, 48, pp. 34-50, DoI: 10.1016/j .foodpol.2014.03.007.

Special Representative on Human Rights (2011) Guiding Principles on Business and Human Rights: Implementing the United Nations "Protect, Respect and Remedy" Framework, Report of the Special Representative of the Secretary General on the Issue of Human Rights and Transnational Corporations and Other Business Enterprises, John Ruggie, un doc. A/HRC/17/31, 21 March. 
Tyler, G. and G. Dixie (2012) Investing in Agribusiness: A Retrospective View of a Development Bank's Investments in Agribusiness in Africa and Southeast Asia and the Pacific, Agriculture and Environmental Services Discussion Paper No. 1 (Washington, D.C.: World Bank), http://www-wds.worldbank.org/external/default/WDSContent Server/WDSP/IB/2013/og/23/ooo356161_20130923144055/Rendered/PDF/810830 REVISEDootingoinoAgribusiness.pdf (accessed on 7 May 2015).

UnCTAD (United Nations Conference on Trade and Development) (2014) World Investment Report 2014. Investing in the SDGs: An Action Plan (New York and Geneva: United Nations), http://unctad.org/en/PublicationsLibrary/wir2014_en .pdf (accessed on 7 May 2015).

- (2009) World Investment Report 2009. Transnational Corporations, Agricultural Production and Development (New York and Geneva: United Nations), http://unctad .org/en/pages/PublicationArchive.aspx?publicationid $=743$ (accessed on 7 May 2015).

UnCTAD and World Bank (2014) The Practice of Responsible Investment Principles in Larger Scale Agricultural Investments: Implications for Corporate Performance and Impact on Local Communities, Agriculture and Environmental Services Discussion Paper No. 8 and UnCTAD Investment for Development Issues Series (Washington, D.C., New York and Geneva: World Bank-UnCtAD), http://unctad.org/en/ PublicationsLibrary/wb_unctad_2014_en.pdf (accessed on 7 May 2015).

UnCTAD, FAO, IFAD, and World Bank (2010) Principles for Responsible Agricultural Investment that Respects Rights, Livelihoods and Resources, A Discussion Note Prepared by FAO, IFAD, the UNCTAD Secretariat and the World Bank Group to Contribute to an Ongoing Global Dialogue, UN doc. TD/B/C.II/CRP.3, 16 April.

Vermeulen, S. and L. Cotula (2010) Making the Most of Agricultural Investment: A Survey of Business Models that Provide Opportunities for Smallholders (Rome, London and Bern: FAO-IFAD-IIED-SDC), http://www.ifad.org/pub/land/agri_investment.pdf (accessed on 7 May 2015). 